\title{
PERCEPÇÃO DOS PROPRIETÁRIOS DE ANIMAIS DE COMPANHIA SOBRE GUARDA RESPONSÁVEL NO MUNICÍPIO DE JABOTICABAL-SP
}

\author{
PET OWNERS PERCEPTION ABOUT RESPONSIBLE OWNERSHIP IN JABOTICABAL, \\ SÃO PAULO, BRAZIL
}

J. H. B. TOSCANO ${ }^{1 *}$, B. F. IZOLA ${ }^{1}$, N. C. MARQUES ${ }^{1}$, F. S. MAIROS ${ }^{1}$, L. ALBINO ${ }^{1}$, E. M. N. PAULA ${ }^{2}$, A. P. R. GRISOLIO ${ }^{2}$, A. A. B. CARVALHO ${ }^{3}$

\section{RESUMO}

O objetivo desse trabalho foi avaliar a percepção dos proprietários de animais de companhia sobre guarda responsável no município de Jaboticabal-SP. Os dados foram obtidos por meio de um questionário, semiestruturado, com 18 questões sobre zoonoses, com foco nas doenças: raiva, toxoplasmose, leishmaniose e leptospirose. Durante um período de 7 dias no mês de setembro de 2015, no Hospital Veterinário "Governador Laudo Natel"- FCAV- UNESP. O software utilizado para tabulação de dados foi o formulário do Google Drive. As respostas foram analisadas por estatística descritiva. Participaram da pesquisa 102 pessoas, sendo $70,6 \%$ do gênero feminino, com faixa etária ente 13 e 77 anos e $80,4 \%$ tinham o $2^{\circ}$ grau completo e/ou estavam cursando ou concluído o ensino superior. Possuem animais de estimação $98 \%$, sendo 133 cães, 56 gatos, 54 aves e 14 outros. Afirmaram levar seus animais ao veterinário 98\%, sendo 5,1\% para rotina, $5,1 \%$ vacinação, $25,5 \%$ quando o animal estava doente e $64,3 \%$ devido a todos os motivos apresentados. Sobre a vermifugação nos últimos 6 meses, 83,8\% afirmaram ter administrado algum medicamento. Além disso, $91 \%$ vacinaram seus animais no último ano, sendo $90,1 \%$ para raiva e $71,4 \%$ polivalente. Somente $27,8 \%$ afirmaram dar a vacina de raiva em campanhas do município, 7,8\% levam em casas agropecuárias e 64,4\% em clínicas veterinárias. Entre os respondentes, 36,6\% não levam seus animais para o reforço anual da vacina polivalente. A castração $(88,2 \%)$ é o método mais utilizado para animais não terem cria. Dos cães que tem acesso à rua (58\%), 62,7\% saem com guia e 8,5\% sem guia e sem supervisão. Foi observado que os proprietários possuem percepção sobre o assunto, e dessa forma, podem assegurar o bem estar dos animais e colaborar para a prevenção das principais zoonoses e de outras doenças, evitando riscos para a saúde pública.

PALAVRAS-CHAVE: ANIMAIS DE COMPANHIA. CÃES E GATOS. HOSPITAL VETERINÁRIO. SAÚDE PÚBLICA.

AGRADECIMENTOS: Departamento de Medicina Veterinária Preventiva e a Liga Acadêmica de Saúde Pública Veterinária (LASP)

ÁREA TEMÁTICA: Saúde pública. 